\title{
A Fuzzy Comprehensive Evaluation Model for Grid Management Performance of Urban Community Party Building in China - Take Z Community as an Example
}

\author{
Liu, GH(Liu, Guihua) 1,a Wei, YT(Wei, Yuanting) 2,b, ${ }^{*}$ \\ ${ }^{1}$ School of Public Affairs and Laws, Southwest Jiaotong University, Chengdu, Sichuan, Peoples R \\ China \\ ${ }^{2}$ School of Public Affairs and Laws, Southwest Jiaotong University, Chengdu, Sichuan, Peoples R \\ China
}

aktflower@126.comb2068921002@qq.com

\begin{abstract}
Keywords: Party Building of Urban Community; Grid Management model; Fuzzy Comprehensive Evaluation
\end{abstract}

\begin{abstract}
With the rapid development and profound changes of China society, traditional social management is encountering with serious challenges. It has become a trend to innovate the ideas and mode of management. Grid mode produced in the practice of grass-roots management is applied to community Party building. In this paper, a corresponding evaluation index system is constructed by combining literature research, social survey and mathematical models for the first time, which is verified by taking $\mathrm{Z}$ community as an example. The results show that the model is feasible and scientific. Finally, in view of the shortcomings, the paper proposes to strengthen the construction of organization team, standardize the operation of model, and perfect the construction of infrastructure and supporting mechanism system, expand the supply of public service.
\end{abstract}

\section{Introduction}

Just as proposed by President Xi in the 19th National Congress of the Communist Party of China: It is of vital importance to strengthen the basic Party building and promote the innovation of setting up organizations and carrying out their activities[1].Under the background of the supply-side structural reform, how to improve the supply quality, expand the effective supply to meet the needs of the masses of people and consolidate the ruling foundation are newly major challenges to the current Party building.

The grid management mode comes into being in time. Chen He argues that grid model is a new method of urban management. Based on the multimedia platform, the Plural-subject are able to communicate with each other immediately by using the modern information network technology, which is conducive to improve the management efficiency [2]. Consequently, the management model is introduced into the Party organization to construct a regional cross-linked network and working mechanism in community [3]. Some scholars proposed to improve the relevant mechanism, integrate the community resources and build a new pattern of service by analyzing the cases of Party building with grid management mode in different regions $[4,5,6,7,8]$. However, there was no research on the management performance of the mode.

Therefore, the purpose of this paper is to provide a reference for the study of this research field. In the following, the research methods will be explained. The next part is the empirical research of $\mathrm{Z}$ community. Finally, the conclusions are drawn.

\section{Methodologies and Process}

Fuzzy Comprehensive Evaluation Model (FCEM) can transform the qualitative evaluation into the quantitative evaluation by using fuzzy mathematics, which mainly used to make a general evaluation of things or objects restricted by many factors [9,10,11]. Referring to the research results in theory and the concrete evaluation index system used in the practice, the whole evaluation 
framework is formed. The analytic hierarchy process (AHP) and fuzzy comprehensive evaluation method are used to analyze the sample data, and finally the evaluation results are obtained. The specific research methodologies and process are shown in figure 1.

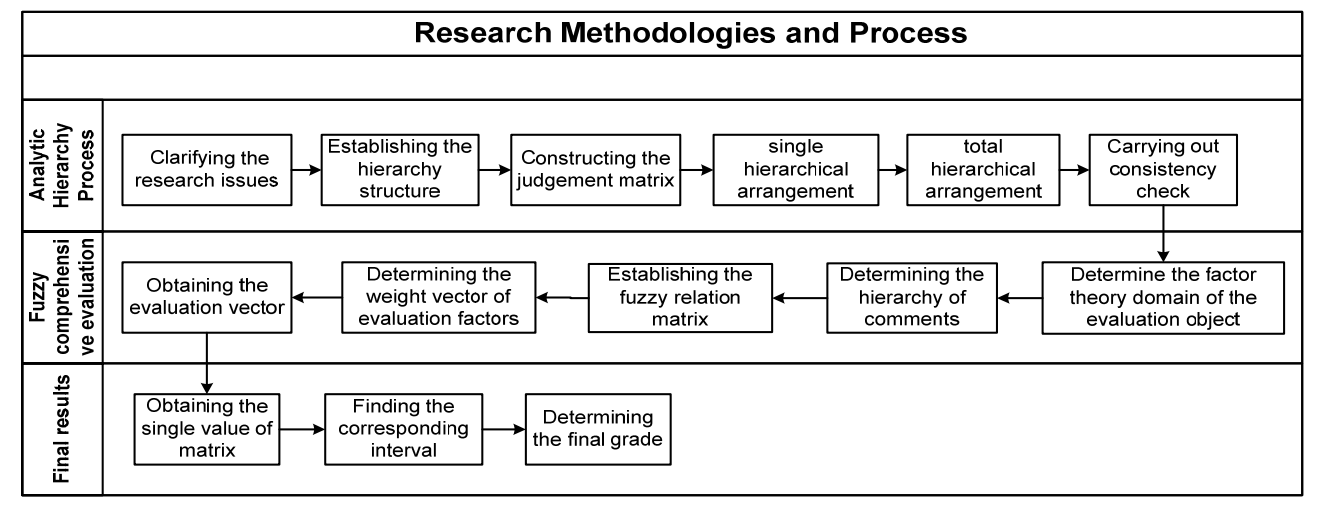

Fig. 1. The research methodologies and process

\section{Constitution and weight of Evaluation Index system}

Table 1. The constitution and weight of performance evaluation index system

\begin{tabular}{|c|c|c|}
\hline First grade indexes ( & Second grade indexes (W2) & Total hierarchical arrangement $(\mathrm{W} 1 * \mathrm{~W} 2)$ \\
\hline \multirow{6}{*}{$\begin{array}{c}\mathrm{U}_{1} \text { : Subject construction } \\
(0.2106)\end{array}$} & $\mathrm{U}_{11}$ : The coverage of grid $(0.0595)$ & 0.01254 \\
\hline & $\mathrm{U}_{12}$ : The leading ability of political thought $(0.3043)$ & 0.06573 \\
\hline & $\mathrm{U}_{13}$ : The role of fighting bastions $(0.1810)$ & 0.03811 \\
\hline & $\begin{array}{l}U_{14}: \text { The perfection degree of institutional mechanism } \\
(0.1286)\end{array}$ & 0.02708 \\
\hline & $\mathrm{U}_{15}$ : The work of building a clean and honest party $(0.1986)$ & 0.04182 \\
\hline & $\mathrm{U}_{16}$ : The innovation ability of Party building practice $(0.1280)$ & 0.02700 \\
\hline
\end{tabular}

Continued from previous Table

\begin{tabular}{|c|c|c|}
\hline \multirow{7}{*}{$\begin{array}{c}\mathrm{U}_{2} \text { : Management service } \\
(0.2409)\end{array}$} & $\mathrm{U}_{21}$ : The openness and transparency of Information $(0.0559)$ & 0.01347 \\
\hline & $\mathrm{U}_{22}:$ The standardization of grid management $(0.7247)$ & 0.17459 \\
\hline & $\mathrm{U}_{23}:$ The efficiency in responding to questions $(0.0954)$ & 0.02298 \\
\hline & $\mathrm{U}_{24}$ : The implementation rate of service commitment $(0.1462)$ & 0.03523 \\
\hline & $\mathrm{U}_{25}:$ The number of activities $(0.1358)$ & 0.03273 \\
\hline & $\mathrm{U}_{26}$ : The innovation and pertinence of services $(0.1569)$ & 0.03780 \\
\hline & $\mathrm{U}_{27}:$ The participation of the masses $(0.3373)$ & 0.08125 \\
\hline \multirow{5}{*}{$\begin{array}{c}\mathrm{U}_{3}: \text { Actual effectiveness } \\
(0.4515)\end{array}$} & $\mathrm{U}_{31}$ : The number of reports from social media $(0.0598)$ & 0.02698 \\
\hline & $\mathrm{U}_{32}$ : The effectiveness of solving practical problems $(0.0805)$ & 0.03635 \\
\hline & $\mathrm{U}_{33}:$ The overall satisfaction of the masses $(0.5113)$ & 0.23087 \\
\hline & $\mathrm{U}_{34}$ : The effect of improving the life quality $(0.2232)$ & 0.10078 \\
\hline & $\mathrm{U}_{35}$ : The effect of improving the living environment $(0.1252)$ & 0.05655 \\
\hline
\end{tabular}

Consistency ratio of judgment matrix: $C R=0.0383$ (Because the $C R$ value is less than 0.10 , the judgment matrix has a satisfactory consistency).

\section{Application of FCEM}

\section{1 data collection}

In order to verify the applicability of the model established in this paper, based on the practice in a community of China, 106 valid questionnaires were collected anonymously in 2017. In the questionnaire, five evaluation grades are set up for each index, which are high, relatively high, general, relatively low and low. 


\subsection{Data analysis}

\subsubsection{Establishing the single factor fuzzy evaluation matrix}

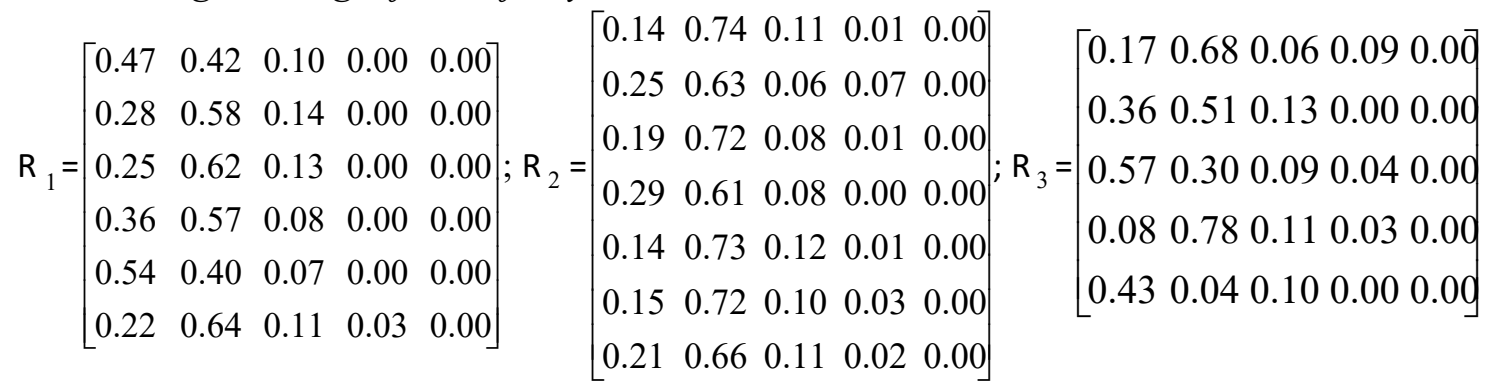

\subsubsection{Determining the vector set of fuzzy subset}

(1) Fuzzy comprehensive evaluation of secondary index

$$
\mathrm{B}_{1}=\mathrm{W}_{1} \cdot \mathrm{R}_{1}=\left[\begin{array}{llllll}
0.339257133 & 0.546666821 & 0.110452973 & 0.003623071 & 0
\end{array}\right],
$$

It is normalized to: $\left[\begin{array}{lllll}0.339 & 0.547 & 0.110 & 0.004 & 0\end{array}\right]$, and other results are as follows:

$$
\mathrm{B}_{2}=\left[\begin{array}{lllll}
0.218 & 0.661 & 0.084 & 0.037 & 0
\end{array}\right], \mathrm{B}_{3}=\left[\begin{array}{lllll}
0.422 & 0.439 & 0.106 & 0.033 & 0
\end{array}\right]
$$

(2) Fuzzy comprehensive evaluation of primary index: $B=W \cdot R=\left[\begin{array}{lllll}0.348 & 0.523 & 0.101 & 0.027 & 0\end{array}\right]$

(3)The single value of the fuzzy vector

According to the weighted average method, the result is $\mathrm{C}=[92.5,77.5,62.5,47.5,20.0]$, so the single value of the fuzzy vector is as follows:

$$
\mathrm{Y}=\mathrm{B} \cdot \mathrm{C}=80.38
$$

The overall evaluation value of the community residents interviewed for the Party building with grid management model in the $\mathrm{Z}$ community is 80.38 , and the corresponding evaluation grade is "Relatively High."

\subsection{Results evaluation}

The final result shows that most residents are satisfied with this mode in $\mathrm{Z}$ community. In addition, the fuzzy comprehensive evaluation results of the three primary indexes are carried out.

Table 2 . The fuzzy comprehensive evaluation results of the primary indexes

\begin{tabular}{cccccc}
\hline First grade indicator & High & Relatively High & General & Relatively Low & low \\
\hline Subject construction & 0.339 & 0.547 & 0.110 & 0.004 & 0.00 \\
\hline Management service & 0.218 & 0.661 & 0.084 & 0.037 & 0.00 \\
\hline Actual effectiveness & 0.422 & 0.439 & 0.106 & 0.033 & 0.00 \\
\hline
\end{tabular}

On the one hand, as shown in the table2, in the fuzzy comprehensive evaluation of the Party building with grid management in $\mathrm{Z}$ community, the highest degree of membership in the three levels is "relatively high", the proportion of which is $54.7 \%, 66.1 \%$ and $43.9 \%$ respectively. The second one was concentrated on the "high" grade, accounting for 33.9\%, 21.8\% and 42.2\% respectively. The proportion of respondents rated as "low" was only $4.0 \%, 3.7 \%$ and $3.3 \%$. These results indicate that the majority of respondents have a high degree of acceptance and satisfaction for the grid management mode of Party building in $\mathrm{Z}$ community.

On the other hand, the main index items with lower evaluation rank are: the number of reports from social media $(9 \%)$, the standardization of grid management $(7 \%)$, the overall satisfaction of the masses $(4 \%)$, the innovation ability of Party building practice $(3 \%)$, the innovation and pertinence of services $(3 \%)$, the effect to improve the life quality $(3 \%)$. To a certain extent, there are still some problems in the current grid management mode of community Party building. For example, the innovation ability is insufficient and the management is non-standard, so it is necessary to continue exploring a new way to perfect the management model. 


\section{Discussions and Conclusions}

Promoting the mode is helpful to make up for the deficiency in the management and service, promote the rational allocation of resources, ensure the legitimate interests of community residents and consolidate the foundation of the ruling. Faced with the complicated and changeable society, the Party building should keep pace with the development. From the perspective of systematic thinking, the construction, operation and management of the mode need the whole subject to participate and cooperate.

Firstly, it is important to update the idea of management constantly and provide a platform for multiple subjects to participate in the mode under the correct value orientation. Secondly, it is necessary to strengthen the scientific planning of the grid according to the local conditions and innovate the management mode in combination with the current situation and practical experience. Thirdly, In order to realize the supply-side structural reform of community public services, we should adhere to taking the overall situations into account and improving the relevant supporting systems by expanding the supply of public service. Finally, According to the development background of big data, the grid management mode of Party building in community should be transform from management to governance, from uni-direction to synergy and from elaboration to precision, which accelerate the innovation and development of grass-roots Party building.

\section{Acknowledgement}

This research was financially supported by the Soft Science Research Project of Chengdu (Grant NO. 2016-RK00-00278-ZF).

\section{Reference}

[1] Jin-ping, X. To win and build a Well-off Society in an All-round way and win the Great Victory of Socialism with Chinese characteristics in the New era. People's Daily, 2017-10-28(001).

[2] He, C. Analysis and practice of Grid Management Mode in Urban Community: a case study of Wenzhou Community. Journal of Wenzhou University (Social Science Edition),vol.04, pp.79-86, 2015.

[3] Jin-qing, Z. Theoretical thinking on the connotation and efficacy of the grid mode of Community Party Building.Shanghai Studies on CCP history and Construction, vol. 12, pp. 43-45, 2005.

[4] Yan-lin, L. Constructing a New pattern of Party Building in Urban Community by Grid Management.Party building, vol.09, pp.29, 2010.

[5] Kai, Z. Research on the implementation path of party building whit grid mode in the community. Journal of the Party School of CPC Zhengzhou Municipal Committee, vol.06, pp. 34-36, 2012.

[6] Chong-ming, H. Reorganization and Social Management Innovation: A Case Study of "Grid Management and Cluster Service". Journal of Public Management,vol.01, pp.63-70+140, 2013.

[7] Yan, X. The Practice and Innovation of Grid Management in Community Party Construction.Marketing Management Review, vol.05, pp.44-45, 2014.

[8] Jian-xin, M. Grid Management and Service : ramming the Foundation of Grass-roots Party Building.Literary Circles of CCP History, vol.14, pp.56-58, 2017.

[9] Deng, C.; Liu, J.; Liu, Y.; Yu, Z. A fuzzy comprehensive evaluation for metropolitan power grid risk assessment (C). In Proceedings of the 2016 International Conference on Smart Grid and Clean Energy Technologies (ICSGCE), Chengdu, China, 19-22 October 2016; pp. 1-5.

[10] Yazdani, A.; Shariati, S.; Yazdani-Chamzini, A. A risk assessment model based on fuzzy logic 
for electricity distribution system asset management. Decision Science Letters, vol.03, pp.343-352, 2014.

[11] Qiu-ju, X.; Ji-qin, N.; Zhong-bin, Su. Fuzzy comprehensive evaluation of multiple environmental factors for swine building assessment and control. Journal of Hazardous Materials, vol.340, pp.463-471, 2017. 